Hollins Martin, C.J., MacArthur, J., Martin, C.R., Mclnnes, R. (2019). Midwives' views of changing to a Continuity of Midwifery Care (CMC) model in Scotland: a baseline survey. Women and Birth.

\title{
Midwives' views of changing to a Continuity of Midwifery Care (CMC) model in Scotland: a baseline survey
}

Caroline J. Hollins Martin ${ }^{1}$

Juliet MacArthur ${ }^{2}$

Colin R. Martin ${ }^{3}$

Rhona J. Mclnnes ${ }^{4}$

${ }^{1}$ Professor in Maternal Health, School of Health and Social Care, Edinburgh Napier University (ENU), Sighthill Campus, Edinburgh, Scotland, UK, EH11 4BN, Email: c.hollinsmartin@napier.ac.uk

${ }^{2}$ Chief Nurse, Research and Development, NHS Lothian, Royal Infirmary of Edinburgh, Edinburgh, EH16 4SA, Email: Juliet.macarthur@nhslothian.scot.nhs

${ }^{3}$ Professor Colin R. Martin, Faculty of Health Sciences, Institute for Clinical and Applied Health Research (ICAHR), Rm 329, Allam Medical Building, University of Hull, Hull, HU6 7RX, UK, Telephone: 01482463708

Email: $\underline{\text { C.R.Martin@hull.ac.uk }}$

${ }^{4}$ Associate Professor in Maternal Health \& Consultant Midwife for NHS Lothian, School of Health and Social Care, Edinburgh Napier University (ENU), Sighthill Campus, Edinburgh, Scotland, EH11 4BN, Email: r.mcinnes@napier.ac.uk

(C2019, Elsevier. This manuscript version is made available under the CC-BY-NC-ND 4.0 license http://creativecommons.org/licenses/by-nc-nd/4.0/ 


\section{Abstract}

Background: There is good evidence that Continuity of Midwifery Care (CMC) is associated with improved clinical outcomes, greater maternal satisfaction, and improved work experiences for midwives. Changes made to the organisation require careful implementation, with on-going evaluation to monitor progress.

Aim: To develop a survey tool that incorporates several validated scales, which was used to collect baseline data prior to implementing a high-quality Continuity of Midwifery Care (CMC) model in Scotland. ${ }^{9}$ This tool gathered data about midwives' personal and professional wellbeing prior to service reorganisation, with a longitudinal study intended to measure change in midwives' reportage across time. This paper reports the baseline data-collection.

Methods: An on-line survey was shared with practising midwives $(n=321)$ in Scotland via the NHS intranet, verbally, email, and paper. The survey elicited midwives views about Continuity of Midwifery Care (CMC); values and philosophies of care; attitudes towards their professional role; personal and professional demographics; quality of life and wellbeing. Psychometric attitudinal scales were scored and free text comments themed according to positive/negative opinions of the new Continuity of Midwifery Care (CMC) model to highlight key concerns to be addressed and identify change barriers or facilitators.

Findings: The majority of midwives indicated support for philosophies underpinning Continuity of Midwifery Care (CMC), which includes physiological birth and providing autonomous midwifery care. Participants also indicated positive attitudes towards their current role and organisation, with some worrying about how the organisation was going to implement the changes required. Worries included, receiving an overburdening workload, being deskilled in certain areas of midwifery practice, and lack of support were litigation to arise.

Conclusion: Midwives support the values and philosophies that underpin Continuity of Midwifery Care $(\mathrm{CMC})$, yet worry about organisational change involved in evolving systems of care. Hence, management require to implement strategies to reduce fears. For example, delivering accurate and honest information, enabling midwives to plan, design and implement changes themselves, and providing emotional and material help. 
Key words: Childbirth, Continuity of Midwifery Care, Midwife, Midwifery Model, Organisational Change, Survey

\section{Statement of significance}

Issue:

Providing Continuity of Midwifery Care (CMC) is the key recommendations of the Scottish Government 'The Best Start' plan. ${ }^{1}$ During implementation there is a need to identify workforce concerns to plan and implement appropriate organisational change strategies when rolling out CMC.

\section{What is Already Known}

For a long time now, midwives have supported the philosophies that underpin CMC, which include physiological birth and providing autonomous midwifery care.

\section{What this Paper Adds}

Participating midwives indicated support for the philosophies that underpin $\mathrm{CMC}$, with many anxious about its introduction. Good change management policies include open consultation, stress management, and building workforce capability. 


\section{Introduction}

In Scotland 'The Best Start' ${ }^{1}$ forward plan proposes implementation of a Continuity of Midwifery Care (CMC) model. The Quality Maternal and Newborn Framework (QMNC) by Renfrew et al. $(2014)^{2}$ was the main driver for service redesign to a CMC model in Scotland. This Lancet Series provides a framework for QMNC that firmly places the needs of women, infants and families at the centre of maternity care provision. Recommendations made are founded upon a definition of midwifery that takes in to account skills, attitudes, behaviours, satisfaction and empowerment of both midwives and women. Findings support a shift from fragmented maternal and infant care, which previously has been concentrated upon identification and treatment of pathology, as opposed to a whole-system approach which provides skilled care for all. ${ }^{2}$ The Changing Childbirth report ${ }^{3}$ was an early unsuccessful attempt to introduce CMC into the UK. In contrast, 'The Best Start $^{1}{ }^{1}$ is a modernistic initiative and has an agenda to be more adaptive and integrative to local situations, and as such is likely to be far more successful in its attempts to introduce CMC.

\section{What does the literature say about CMC?}

$\mathrm{CMC}$ is consistently associated with improved outcomes, with a Cochrane review identifying more spontaneous vaginal births, fewer inductions and interventions during labour, and greater satisfaction with care compared with other models. ${ }^{4}$ The evidence for $\mathrm{CMC}$ is unequivocal, as this Cochrane meta-analysis of 15 RCTs involving over 17000 women by Sandall et al. ${ }^{4}$ has demonstrated. An evaluation of caseload midwifery in one socio-economically disadvantaged area of London (The Albany Practice), similarly identified higher spontaneous births and breastfeeding, and lower preterm births and interventions compared with hospital-based care. ${ }^{5} \mathrm{CMC}$ has also been associated with improved work experience for midwives. ${ }^{6}$

In response to evidence which supports the benefits of implementing $\mathrm{CMC}$ models, ${ }^{2,4}$ several countries are in the process of restructuring their midwifery services to accommodate CMC models. Australia, New Zealand and the UK are the forerunners, with the Netherlands already 
having an established system. Accompanying incumbent restructuring are evaluations of service re-design to $\mathrm{CMC}$ models.

Menke et al. (2014) ${ }^{7}$ explored Australian midwives' perceptions of organisational structures and how they influence midwives' ability to provide caseload care. Findings showed that the participating midwives believed they provided an excellent service and gained satisfaction from working in partnership with women. This was accompanied by some frustrations surrounding lack of organisational support and a culture of blame dominated by medicine. ${ }^{7}$ This paper examined midwives' perceptions of organisational structures and processes of care when working in a caseload model. However, there remains limited understanding of the impact of organisational structures and processes of care on midwives' wellbeing when working in a CMC model.

Forster et al. (2019) ${ }^{8}$ surveyed women's experiences of homebirth programs, with a high percentage rating care as 'very good'. Women appreciated being encouraged to express their feelings and afforded control, accompanied by positive experiences of midwife support. ${ }^{8}$ This paper was attentive to the views of childbearing women engaged in a CMC style model of care. The authors, however, did not explore midwives' wellbeing when providing CMC through homebirth programs.

Hewitt et al. (2019) ${ }^{9}$ took a qualitative interpretive approach towards exploring attributes Australian midwifery leaders $(n=8)$ identified as essential for effectively managing a Midwifery Group Practice (MGP). The ideal MGP manager was seen to be one who stands up for midwives and women and is educated and supported in their role. ${ }^{9}$ Essentially, this paper focused upon leaders' qualities and not the attitudes and wellbeing of midwives engaged in this CMC style model of care. Maintaining midwives' wellbeing across time is essential for retention of staff and sustainability of a model, with quality leadership key to success.

Fernandez Turienzo et al. (2019) ${ }^{10}$ explored implementation of CMC models for indigenous Australian women. Findings emphasised the need to ensure better health outcomes for mothers and babies, with it crucial to promote culturally competent and safe public health models in which midwives work collaboratively with multidisciplinary teams. ${ }^{10}$ Again, this paper does not consider 
midwives attitudes and wellbeing when working in a CMC model. It does however provide useful insights for the development and implementation of similar models in Scotland.

Cummins et al. (2019) $)^{11}$ conducted focus groups to explore value placed upon using the Quality Maternal and Newborn Care (QMNC) Framework for services users and providers. Good quality care was considered to be facilitated by fostering connections, providing flexibility, and being afforded choice and control. Perceived barriers included contested care and requiring greater preparation for unexpected outcomes. ${ }^{11}$ Again, this paper did not explore midwives attitudes and wellbeing when working in this QMNC model of midwifery-led continuity of care provision.

Dawson et al. (2016) ${ }^{12}$ conducted a survey of maternity managers' provision of CMC throughout Australia. Respondents ( $n=149$ ) ranged from metropolitan, regional and remote areas, and from hospitals with small to large birth numbers. Findings revealed that $31 \%$ of hospitals offered caseload midwifery and an estimated $8 \%$ of women received caseload care. Funding and support for establishing new models was seen as the main barriers to implementation. ${ }^{12}$ With similarity to Scotland, this was the first study to explore caseload implementation at a national level in Australia, however it did not explore midwives' attitudes and wellbeing whilst engaging with the new model of care.

Sidebotham et al. (2015) ${ }^{13}$ explored Australian midwives' perceptions of their role and how they conceptualised a change in working patterns and environment to provide higher levels of continuity of care. In general, the participating midwives endorsed reforms towards providing CMC. However, the majority felt powerless to effect change and in response passively accepted the status quo of their employing organisation. In order to promote the growth of evidence-based $\mathrm{CMC}$ models, strong midwifery leadership is required to empower midwives to re-conceptualise their roles and work patterns, which will enable them to engage with reform. ${ }^{13}$ In order to promote the growth of evidence-based CMC models, midwives need to work to their full scope of practice, with considering their attitudes towards and wellbeing an essential component of this.

McCourt (2018) ${ }^{14}$ carried out an ethnographic study to investigate how Alongside Midwifery Units (AMU) $(n=54)$ to adjacent obstetric units are managed. The units studied were recognised for providing safe quality care. Nonetheless, AMU's were providing care for only one third of women 
who were eligible to plan birth outside the obstetric unit. Clearly, developing AMU's involves alignment of physical, professional and philosophical boundaries. Other factors that also require attention include, increasing staff training and support, developing integrated continuity-based staffing models, and ensuring that AMUs are positioned as a core service rather than a marginal one. ${ }^{14}$ This paper acknowledges that integrated staffing, including caseload community teams, may mitigate tensions. Although unchartered in this paper, exploring midwives' attitudes and wellbeing is an important component of changes in any service provision.

In relation to evaluation of services, women who complete Care Quality Commission (CQC) surveys generally provide better scores when they have received CMC (Care Quality Commission, 2019). ${ }^{15}$ Contextualised in Scotland, quality of maternity care evaluates well, ${ }^{1}$ with past surveys reporting that many women prefer to see fewer midwives during their maternity care journey. ${ }^{1}$

Although all the critiqued studies have cross-transferable concepts that are relevant to implementation of CMC in Scotland, all took place geographically elsewhere, and none explored midwives' attitudes and wellbeing before during and after engaging with change in practice to a $\mathrm{CMC}$ model. This is an important and underexplored area of changing to a CMC model. Fit for purpose, Mclnnes et al. $(2018)^{16}$ developed an evaluation tool for measuring midwives' views about working within a CMC model, which elicits views about $\mathrm{CMC}$, its values and philosophies, attitudes towards role, personal and professional demographics, and quality of life and wellbeing. The intention is for managers to use this tool to evaluate implementation of $\mathrm{CMC}$ before, during and post completion of its implementation. ${ }^{16}$

The most recent Royal College of Midwives workforce survey (RCM, 2016) ${ }^{17}$ illustrates that within the current system midwives report high levels of workplace stress, with those who have left the profession reporting poor staffing, being unable to provide quality care, increased workload, insufficient managerial support, and poor working conditions as reasons for departing the profession. ${ }^{17}$ Other drivers, such as changing population demographics (e.g., co-existing morbidities, obesity and lifestyle changes) and workforce challenges (e.g., difficulties with recruiting \& retaining midwives) together indicate that the current model of midwifery care provision maybe unsustainable. 


\section{Cost effectiveness of CMC models}

Critical evaluation of the cost-effectiveness of CMC models is an important consideration in the review and reform of the maternity services. Friedman et al. $(2015)^{18}$ carried out a review of data about the costs of midwife-led versus physician-led intrapartum care. Several randomized and other well-designed prospective and retrospective studies conducted in developed countries have shown that $\mathrm{CMC}$ is significantly less medically intensive. For example, $\mathrm{CMC}$ results in a reduced number of caesarean sections, episiotomies, produces shorter hospitalization, and generates lower costs compared with physician-led care. ${ }^{18}$ These findings have been confirmed in a systematic Cochrane review and meta-analysis of 11 randomized trials of $(n=12,276)$ low to mixed risk pregnant women from four developed countries (Australia, Canada, New Zealand, UK). ${ }^{19}$ In this meta-analysis, women receiving midwife-led intrapartum care were $14-19 \%$ less likely to receive regional analgesics, have an episiotomy, or instrumental birth. They were also $16 \%$ less likely to receive intrapartum analgesia or anesthesia and were more likely to have a normal delivery. Differences in rates of caesarean section were not significant between the two groups. ${ }^{19}$

\section{What does 'The Best Start' model look like?}

The motivation of 'The Best Start' ${ }^{1}$ in Scotland is to craft a refreshed model of care and approach to midwifery provision, with 'continuity of carer' defined as 'having a known carer' throughout pregnancy, during childbirth and post-delivery. Key recommendations of the new CMC model are that all women, partners and families ${ }^{1}$ should be provided with:

- Continuity of carer.

- Person-centred maternity and neonatal care.

- Accessible and appropriate services.

In response to these factors, the current maternity and neonatal services require redesign in Scotland, which will involve workforce planning, role development, and high-quality education and training. Considerations include supporting changes to the transport services, remote and rural care, telehealth and medicine, workforce planning, education and training, quality improvement, and introduction of national data, IT and electronic records. The new Scottish CMC models will differ marginally across the 14 Scottish Health Boards, to accommodate remote and rural variables. The model includes the midwife as the lead professional starting from initial booking up to and including early days of parenting. ${ }^{4}$ This new proposed CMC model in Scotland differs to 
many other countries around the world (e.g., US), which continue to follow a medical model of maternity care provision (WHO, 2016). ${ }^{20}$

Implementing change on this scale demands ongoing monitoring and evaluation, and with this in mind our aim was to develop a survey tool that incorporates several validated scales, which was then used to collect baseline data prior to implementing a high-quality Continuity of Midwifery Care (CMC) model in Scotland. ${ }^{16}$ This tool gathered data about midwives' personal and professional wellbeing prior to service reorganisation, with a longitudinal study intended to measure change in midwives' reportage across time. This paper reports the baseline datacollection.

\section{Method}

A realist informed on-line survey was conducted to test and refine program theory, at the same time as providing a baseline assessment prior to implementation of CMC in a local setting. Realist evaluation is increasingly applied to evaluate complex healthcare interventions, because it seeks to provide more explicit and in-depth understanding of what works for whom and in what circumstances. ${ }^{21}$ Quality Improvement Team approvals were obtained for conducting this baseline evaluation and all participants were freely able to choose whether to opt in.

\section{Participants}

Approximately 430 midwives employed in one Scottish Health Board were asked to complete the survey, with 321 (75\%) responding.

\section{Setting}

The Health Board was chosen because it is an early adopter site selected by the Scottish Government to test maternity service redesign to a CMC model. The Health Board has a population of approximately 800,000 , covering both urban and rural settings and around 9,500 births per year. There are two hospital maternity units, both of which are modern teaching hospitals (Hospital A has around 6000 births per year; Hospital B has around 3-4000 births per year) and community midwifery services are provided across a wide geographical area. The Health Board selected is comprised of three settings: Hospital A, Hospital B, and community.

\section{Survey tool development}

(C2019, Elsevier. This manuscript version is made available under the CC-BY-NC-ND 4.0 license http://creativecommons.org/licenses/by-nc-nd/4.0/ 
Development of the midwives' survey tool is reported in Mclnnes et al. (2018), ${ }^{16}$ with process and content informed by a literature review, the framework for high quality midwifery care (Renfrew et al., 2014), ${ }^{2}$ stakeholder interviews, and group discussions with service providers and users, all of which facilitated development of categories and content. Draft versions of the new survey tool were tested and further developed following feedback. The final version, which includes several valid and reliable scales, gathers information about midwives: (1) current role, location and travel, (2) their beliefs about MCC and its underpinning philosophies, (3) attitudes towards professional role, (4) demographics, and (5) quality of life and wellbeing (Table 1).

TABLE 1

\section{Attitudes to 'The Best Start' CMC Proposal}

Midwives were invited to respond to open text questions:

(1) (a) What excites you about the model?

(b) What opportunities do you see?

(c) What concerns do you have?

(2) How might the model impact on your personal life?

(3) What resources, training or experiences would you need to work in the model?

\section{Data-collection}

The participant information sheet and consent form was emailed to the Chief Midwife and team leaders within the Health Board, who further cascaded them by email to all midwives. Information about the survey was also shared verbally and in flyers, along with the offered option to complete a paper version. A survey link was also emailed to members of the Health Board's Midwives Research Group and posted on relevant Facebook sites. During completion, participants could opt out of providing personal demographic details through choosing a 'prefer not to say' option or omitting to answer the question.

\section{$\underline{\text { Data-analysis }}$}

Descriptive statistics and Chi-square analysis was used to analyse personal and professional demographic data by location. The psychological scales and subscales that assess attitudes, satisfaction and empowerment were scored as per authors' instructions. Comparison of scale data (C2019, Elsevier. This manuscript version is made available under the CC-BY-NC-ND 4.0 license http://creativecommons.org/licenses/by-nc-nd/4.0/ 
between groups (sites) was analysed using one-way-between-subjects analysis of variance (ANOVA). ANOVA was selected because it permits partial variance comparison within and across populations and subgroups. In the event of a statistically significant overall ANOVA omnibus test, post-hoc testing determined where group differences could be found using the Bonferroni procedure to control for type 1 error. Statistical significance was set at equal to or less than 0.01 . Free text comments were grouped according to positive/negative opinions of the new MCC model, key concerns, and potential barriers/facilitators to organisational change.

\section{$\underline{\text { Results }}$}

A total of 321 midwives completed the survey on-line $(n=314)$ or paper $(n=7)$, with 3 paper copies discounted due to extensive missing data, leaving $(n=318)$ for analysis. It should be noted that since the $\mathrm{CMC}$ model has yet to be implemented in the study sites, participants will lack direct experience of this approach to care. Fully complete sub-scale measures were only included in analysis, which explains why participant numbers vary between reported scales and variables. Personal and professional demographic variables for the whole survey are summarised (Table 2).

\section{TABLE 2}

Further analysis was conducted by location (maternity hospital or community), with significant differences between groups specified mostly by a value of $(p<0.05)$.

\section{Wellbeing}

Participant wellbeing was measured using the short Warwick Edinburgh Mental Well-Being Scale $\left(\right.$ SWEMWBS) ${ }^{22}$ and the Professional Quality of Life scale (ProQOL) ${ }^{23}$ (Table 3). The SWEMWBS scale scores between 7-35, with higher scores indicating more positive wellbeing. In this Health Board the midwives' mean score was $25.8 \pm 4.1$ (unconverted, alpha $=0.85$ ), with no conversion necessary when scale and calculation method is specified.

ProQol measures Compassion Satisfaction (positive aspect of helping, i.e., pleasure and satisfaction derived from helping and care giving), Burnout (negative aspects of helping, such as feeling worn out, exhausted, fatigued, frustrated, depressed, hopeless \& inefficient) and Secondary Traumatic Stress (exposure to traumatic, stressful events and/or feeling afraid). Each of these sub-scales is scored to indicate low $(\leq 22)$, average (23-41), or high $(\geq 42)$ levels of the construct. The survey participants scored average (64\%) or high (35\%) high levels of Compassion (C2019, Elsevier. This manuscript version is made available under the CC-BY-NC-ND 4.0 license http://creativecommons.org/licenses/by-nc-nd/4.0/ 
Satisfaction (higher scores are more positive); Burnout was scored as low (50\%) or average (50\%) and Traumatic Stress as low (69\%) or average (30\%); lower scores are more positive for Burnout and Traumatic stress (alphas $=0.80,0.89,0.85$ respectively) .

\section{Attitudes towards professional role, values and philosophies}

Pre-validated scales measured attitudes towards: Birth Attitudes Scale (BAS), ${ }^{24}$ Perceptions of Empowerment-Midwifery Scale (PES-M), ${ }^{25}$ Attitudes to Professional Role Scale (APRS), ${ }^{26}$; attitudes towards midwifery and the organisation (Professional Role; RCM, 2016) ${ }^{17}$; and two questions on birth 'as a normal process' and birth choice from the RCOG survey (Thomas \& Paranjothy, 2001). ${ }^{27}$ The results for each of the scales are summarised in the rest of this section and are detailed in Table 3.

\section{TABLE 3}

Cronbach alpha for the BAS was 0.56. Alphas for the APRS satisfaction, support, client interaction and professional development sub-scales were $0.81,0.70,0.76$ and 0.67 respectively (total scale APRS alpha $=0.90)$. Alphas for the PES-M autonomy/empowerment, manager support, professional recognition and skills/resources sub-scales were $0.73,0.88,0.75$ and 0.60 respectively (total scale PES-M alpha $=0.86$ ). Alphas for the PES-M autonomy/empowerment, manager support, professional recognition and skills/resources sub-scales were $0.73,0.88,0.75$ and 0.60 respectively (total scale PES-M alpha $=0.86$ ). Alphas for the Professional Role midwifery and organisation sub-scales were 0.68 , and 0.84 respectively (Professional Role all-items alpha $=0.88$ ).

\section{Continuity of Carer Scale (CoCS)}

Derived from the survey tool, ${ }^{16}$ alphas for the CoCS attitudes/beliefs, logistics/practical and outcomes sub-scales were $0.62,0.58$ and 0.73 respectively (total CoCS alpha $=0.82$ ).

Overall participants indicated positive attitudes towards physiological birth, their current role and their organisation, as well as satisfaction with their professional role as a midwife. They also indicated positive empowerment (PES-M) scores (Table 3), with subscale data showing that many felt empowered educated and supported to do their job and thus felt able to support and empower women. The highest PES-M sub-scale score was for support from colleagues and the lowest related to feeling professionally recognized by their manager and provided with manager 
support (Table 3). While respondents indicated overall positive attitudes to their professional role in the APRS (Table 4), there was variation within subscales, with highest scores relating to overall satisfaction with current role and confidence in having skills to do the job. The lowest scores related to having the time to do the job properly or provide the care women needed and work stress.

\section{TABLE 4}

\section{Attitudes to and experiences of CMC models}

Participants were invited to consider their experiences of working in different types of midwifery care models in a range of continuity statements developed from stakeholder interviews ${ }^{16}$ (Table 6). Most participants had some experience of relationship continuity as part of antenatal/postnatal care provision (72\%). Fewer had experienced caseload midwifery either within small midwifery group practice (15\%) or as one-to-one caseload care (6\%).

Responses to statements indicated negative attitudes to CMC and to the proposed 'The Best Start' model (Table 5), with lowest scores relating to concerns about developing stress and burnout and impact upon personal life. The most positive scoring statement indicated that the midwife already provided continuity of carer.

\section{TABLE 5}

\section{Variation by geographical and professional setting}

In a realist evaluation, it is usual to contextualize each geographical setting to allow comparison, and so each sub-scale has been analysed according to location (Table 3). Due to the enormity of task, this paper does not report on psychometric performance of the assembled instrument.

Significant differences between Birth Attitude Scale (BAS) scores by location was found $(F(2,223)=$ 9.69, $p<0.001, \eta^{2}=.08$.). Post-hoc analysis revealed that BAS community scores were significantly higher than Hospital A BAS scores ( $p<0.001)$. Overall, significant differences were also observed for the CoCS attitudes/beliefs, $F(2,238)-3.31, p=0.04, \eta^{2}=.03$, logistics/practical, $F(2,238)=21.12, p$ $<0.001, \eta^{2}=.15$, and outcomes, $F(2,238)=3.80, p=0.02, \eta^{2}=.04$ sub-scales and the CoCS total score, $F(2,238)=8.16, p<0.001, \eta^{2}=.06$. Post-hoc analysis revealed that CoCS attitudes/beliefs community scores were significantly higher than Hospital A attitudes/beliefs scores $(p=0.04)$, and again a similar group post-hoc group difference was observed for the CoCS logistics/practical sub- 
scale $(p<0.001)$. Hospital B participants were observed to have significantly higher CoCS outcome sub-scale scores compared to both Hospital A based $(p=0.01)$ and community-based $(p=0.03)$ participants. Hospital B participants had statistically significant higher total CoCS scores than Hospital A based $(p=0.03$ ) participants. Similarly, statistically significant higher total CoCS scores were observed in community-based participants compared with Hospital A based participants ( $p<$ 0.001). Overall significant differences were also observed for the PES-M manager/support, $F(2$, $208)=19.07, p<0.001, \eta^{2}=.08$ sub-scales (see Table 3 ). Post-hoc analysis revealed that PES-M manager/support community scores were significantly higher than Hospital A manager/support scores $(p<0.001)$, as were Hospital B scores on this sub-scale compared to Hospital A scores ( $p=$ 0.001). Post-hoc analysis also revealed that PES-M autonomy/empowerment community scores were significantly higher than both Hospital A $(p<0.001)$ and Hospital B scores $(p=0.02)$ on this sub-scale measure.

Table 4 summarises the inferential analysis of the APRS, ${ }^{26}$ total and sub-scale scores. Statistically significant differences were observed for the APRS support, $F(2,213)=5.38, p=0.005, \eta^{2}=.05$, interaction, $F(2,213)=6.94, p=0.001, \eta^{2}=.06$, and development, $F(2,213)=8.40, p<0.001, \eta^{2}=$ .07 , sub-scales and the APRS total score, $F(2,213)=7.14, p=0.001, \eta^{2}=.06$. Post-hoc analysis revealed that APRS support sub-scale community scores were significantly higher than those of the Hospital B group $(p=0.006)$. APRS interaction sub-scale scores were significantly higher in the community group than both the Hospital A group $(p=0.02)$ and the Hospital B group $(p=0.003)$. Similarly, APRS development scores were significantly higher in the community group compared to the Hospital A group $(p<0.001)$. Total APRS scores were significantly higher in the community group compared to both the Hospital A $(p=0.005)$ and Hospital B $(p=0.009)$ groups. No other statistically different overall ANOVA findings were observed.

Measures stratified by category from scores are summarised (Table 5). Significant differences in the neutral compared to physiological birth were observed as a function of participant site category. No other statistical significant observations were observed.

Evaluation of previous experience of working in continuity models revealed significant differences in antenatal continuity, antenatal and postnatal continuity, and midwifery group practice caseload care as a function of participant site $(p=0.008-p<0.001)$ (Table 6). Differences between 
Midwifery Group Practice and Caseload Care, and relationships with attitudes to the new CMC model is worthy of further exploration, which would involve further statistical modelling and so is not part of this report.

\section{TABLE 6}

\section{Attitudes to 'The Best Start' CMC Proposal}

Many comments made by participants overlapped categories and so have been summarised in the titled sections that follow. The intention is to produce a full qualitative report. Presented below is a mere flavour of the midwives views, with a total of $(n=245)$ midwives providing qualitative responses:

- Midwives who totally support the new CMC model $(n=19)$.

- Midwives with concerns about CMC implementation ( $n=67)$.

- Midwives against the new CMC model $(n=149)$.

- Midwives perceived impact on their personal life $(n=244)$

*Perceive CMC will have a positive impact on their personal life $(n=7)$

*Perceive CMC will have a negative impact on their personal life $(n=211)$

*Do not know as do not have enough information $(n=22)$

\section{Professional role}

The importance of providing CMC and having continuous relationships with women was acknowledged. However, some thought that providing effective continuity, quality relationships and high standards of care could prove difficult within the new CMC model. Those favouring implementation of CMC could see opportunities to work autonomously, with this approach utilising the full spectrum of midwifery and allowing them to build enhanced relationships with women across their childbearing experience. Conversely, having specialist skills and being confident in one particular area of midwifery (antenatal, intranatal, postnatal) was highlighted as a reason not to change practice. Deploying midwives to more general cross-spectrum practice was considered by some to affect quality and safety of care provision, particularly within high-risk contexts. Feeling de-skilled in specific aspects of midwifery care acted as a barrier for some, whilst others saw CMC as an opportunity to up-skill and take a more holistic approach to care provision.

\section{Workload, stress, burnout and wellbeing}


Comments were made about inadequate staffing having a negative impact upon midwives' worklife balance. Key concerns included on-call being viewed as an unpredictable 24/7 commitment, which would impact upon ability to function and affect wellbeing through night-working interrupted sleep and having limited space to recover. Community midwives, who already practise on-call, were opposed to an increase, whilst others completely rejected this way of working. Accommodating on-call in a CMC model was considered difficult for some due to childcare commitments and time taken to travel to varying work locations. In addition, midwives expressed fears about added economic costs, need for support to develop essential skills and build confidence, and lone-working compromising personal safety, all of which could augment preexisting stress.

\section{Choice and control}

Many respondents indicated that they lacked choice and control about how they themselves should practice within the new CMC model, with a lack of information provided about operational aspects. Language used to express these views involved:

'Being forced to'.

'Being compelled to'.

'I feel as though we have had no say'.

Some midwives expressed concern about where they would be geographically located, and potential to impact upon commitments at home. Positive comments related to becoming a named midwife and providing women with choice and control during their pregnancy journey:

'Good for women to have a primary midwife'.

'Continuity is definitely positive for women'.

'Women will benefit from continuity of carer throughout, as able to really tailor best care to women'.

\section{Implementation risks}

Some midwives identified the need for specialised training, skills updates and experiences that would build their confidence to work as caseload midwives, with such input requiring managerial support and financing. Upskilling is a requirement of both full-time and part-time midwives, but 
the additional necessary study leave has potential to increase the pre-existing high 'absence from work' record.

\section{Discussion}

The most striking finding was that while the majority of midwives held positive attitudes towards the philosophies and values underpinning CMC (i.e., being supportive of physiological childbearing and autonomous midwifery practice), they also held reluctant attitudes towards introducing the model into their own practice. These appear to be contradictory, given the evidence that CMC supports physiological processes of childbirth, psychological wellbeing ${ }^{4,5}$ and autonomous midwifery practice. ${ }^{28}$ Within the data, quality of care, maternal satisfaction, and delivery of continuity were already considered present in practice, albeit to varying degrees. Other explanations for midwives' incongruent views may include limited understanding of how a CMC model might work ( $<72 \%$ of the sample had actual experience of $\mathrm{CMC}$ ) and prior negative experiences of attempts to implement caseload midwifery. ${ }^{16}$

Differences were considerable between hospital and community based midwives in relation to exposure and experiences of providing continuity of care and carrying a caseload (Table 6). These differences may reflect demographic variation (Table 1) or may be due to variation in organisational methods of working between midwives employed in hospitals and those who work in the community. Most community midwives already forge relationships with women and their families and have some control over their diaries about when and where they do their visits. They also have some control over how they fit their working patterns around their own family life. In contrast, hospital based midwives more often work in specialised areas of practice and have the certainty of knowing their shift patterns. Ultimately, changing to a CMC model requires hospital and community midwives to work together to create the transformational change that has been requested in 'The Best Start' (SG, 2017)..$^{1}$ In light of the overwhelming evidence ${ }^{4,5}$, now is the time to actually make this happen.

\section{Role of the organisation}

Organisational factors influence acceptance of change, with management requiring to implement strategies to reduce stress from increased workloads (RCM 2016), ${ }^{17}$ and reduce midwives fears surrounding overburden that could progress to burn-out. ${ }^{29}$ The current silo model of maternity C2019, Elsevier. This manuscript version is made available under the CC-BY-NC-ND 4.0 license http://creativecommons.org/licenses/by-nc-nd/4.0/ 
care has been the norm for several decades, with midwives practicing within specialised locations (i.e., antenatal/intranatal/postnatal/neonatal), as opposed to taking a holistic approach across the childbearing spectrum. Many midwives perceive themselves as deskilled in some areas of midwifery practice, ${ }^{30}$ which is compounded by fear of lack of support from management when litigation arises. ${ }^{31}$ Management require to address these issues in a positive and determined way. Some midwives appeared to be unable to imagine themselves successfully juggling work and home life, whilst working within an $\mathrm{CMC}$ model. Findings reflect similar barriers to implementing CMC models in Australia, ${ }^{12}$ with Sidebotham et al. $(2015)^{13}$ highlighting how midwives in their study were unable to conceptualise benefits offered and expressed preference to maintain the present status quo. Overcoming these obstacles, now is the time for midwives to prodigiously commit to their vocational role.

Political and ideological factors compound resistance to inaugurating CMC. ${ }^{32}$ Nonetheless, this is the time for midwifery to be bold and implement models that are supported by the evidence.

Effective organisational change management comprising a structured approach, staff involvement, on-going information, responsive leadership and being open to unanticipated positive and negative outcomes ${ }^{33}$ has been identified as key in other CMC studies. ${ }^{34}$ Considered sequential steps are required, followed by careful evaluation along the way. Mishandling planned change runs the risk of arousing uncertainty, frustration and fear. In this study, some midwives have expressed defensive and negative attitudes towards implementation of the new CMC model. ${ }^{16}$ This broadly reflects what other authors have identified as key when implementing CMC. For instance, in Australia uptake of CMC has been patchy with barriers in this context including a lack of interested or available midwives and of funding while uptake is more likely where there is financial and organisational support. ${ }^{12}$ Measures to overcome such resistance to change ${ }^{32}$ could potentially include:

- Delivering accurate and honest information.

- Enabling midwives to plan, design and implement changes themselves.

- Providing emotional and material help.

- Offering incentives to overcome actual or potential resistors. 
Other solutions may lie within the remit of occupational psychology and are explained in the scientist-practitioner model, ${ }^{34}$ which focuses upon motivation, job satisfaction, safety and health, group effectiveness, and support provision. Motivation reflects the energy a person applies to initiate work-related behaviour, through determining its form, direction, intensity and duration' ${ }^{35}$ In this instance, since many of the participating midwives are disinclined towards operating within a CMC model, positive opportunities to build engagement of already busy staff should be considered. ${ }^{36}$ There are three psychological processes involved in gaining reward; (1) Initiating action through desire for something to work, (2) Gaining willingness to take the path, and (3) Acceptance of the amount of energy required to make it work. ${ }^{37}$ Interventions to reduce stress can sequentially increase productivity, performance, health and wellbeing. ${ }^{38,39}$ These considerations are important, because stress arouses emotions (e.g., conflict triggers anger), which in turn can motivate unhelpful behaviors. ${ }^{40}$ Transformational leadership involves creating a positive climate, with policies, practices, and procedures designed to protect employees' psychological health. ${ }^{41,42}$

The growing evidence of improved emotional well-being and job satisfaction for midwives working within CMC models is worthy of dissemination. For example, Danish midwives have reported lower levels of burnout, depression, and anxiety, ${ }^{43}$ which is supported by evidence from Australia ${ }^{28,44}$ and New Zealand. ${ }^{6}$ High levels of professional fulfilment and role satisfaction are reported by midwives working in CMC models. ${ }^{6,28,26,43,44}$

Engaging in CMC can be empowering. ${ }^{28,45}$ and may improve levels of wellbeing and job satisfaction through midwives acting as advocates who provide holistic care and build meaningful relationships with women, families, and the multidisciplinary team. ${ }^{28,45}$

Organizational support systems influence team effectiveness, which include providing essential facilities, equipment, information, training, and leadership. ${ }^{46}$ Organizational culture that supports and rewards midwives who value teamwork and sustain positive attitudes is beneficial, ${ }^{47}$ with team building activities fostering self-confidence, group cohesiveness and effectiveness. ${ }^{48}$

\section{Strengths and Limitations}

The $75 \%$ response-rate from this on-line survey was good and may mirror importance of the topic to participants. The free text boxes also provided elaborative triangulated explanatory data for (C2019, Elsevier. This manuscript version is made available under the CC-BY-NC-ND 4.0 license http://creativecommons.org/licenses/by-nc-nd/4.0/ 
closed-ended quantitative responses. One limitation is that the findings are not generalizable, with analysis beyond context constrained by data-collection methods. A further limitation is that it cannot be guaranteed that the study sample is completely representative of the wider Scottish midwifery workforce until the CMC model is implemented in Scotland as whole, thereafter providing the opportunity to allow regional comparisons to be made. In relation to the statistics, although they showed that the tool gathered reliable data for many of the sub-scales, the Cronbach's alpha for the BAS was 0.56 . Hence, this result needs to be considered with caution and was a limitation of this study. Within each of the sub-scales, there were some Cronbach alpha's $(<.70)$, which suggest that the scale is stronger when all components are used as a total scale and not simply as subscales. Clearly, further work is required to determine the reliability characteristics of those sub-scales to determine whether any further modification to the instrument is required.

\section{$\underline{\text { Implications for practice }}$}

Implementing CMC on a national scale in Scotland requires significant service re-organisation. Such restructuring is a 'big ask' of midwives, particularly when current services are stretched and stress is a main contender for midwives leaving the profession. Hence, applying change management theory is important. In the first instance, it may be beneficial to provide choice about whether the midwife wants to work in a CMC team, because engaging motivated staff will facilitate service transformation. Evidence surrounding improved emotional well-being, job satisfaction, professional fulfilment and greater professional empowerment for midwives working within CMC models also requires emphasis. Sharing successful stories and experiences of 'early adopter' midwives who are already working in CMC in similar contexts may help sway negative attitudes. Prerequisite of any NHS change management process is quality communication, staff involvement, responsive leadership, sourcing government resources to manage critical change effectively, and evaluation. In addition and in response to evolving midwifery practice, there is also the increasing need to adapt university curriculum to respond adaptively to the changing needs of CMC implementations. ${ }^{49}$

A clear foundation of trust is the glue that binds managers to midwives and creates capacity for organizational and leadership success. This foundation of trust is built upon three factors; credibility, respect, and fairness: ${ }^{50}$ 
Credibility includes open and accessible communications, organizational competence in coordinating human and material resources, and integrity in carrying out vision with consistency.

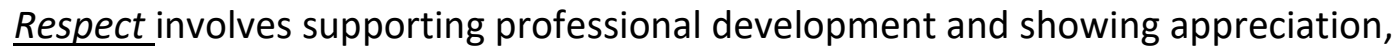
collaborating with midwives in decisions, and caring for them as individuals with personal lives.

Fairness embraces balanced treatment of all midwives in terms of rewards, absence of favouritism in hiring and promotions, and lack of discrimination in process of appeals.

\section{Conclusion}

This study reports contradictory views, with the majority of participating midwives holding overwhelmingly positive attitudes towards the philosophies and values that underpin CMC. Simultaneously, these midwives reported reluctant attitudes towards introducing CMC into their own clinical practice. In addition, participants provided positive reports of their role as midwives and about the organisation, with many writing comments that support the idea of implementing the CMC model. Main concerns surrounded potential impact of continuity/caseload care upon midwives' personal lives and work-life balance. In the past, implementation of CMC models within the NHS have been relatively small-scale, and have engaged motivated midwives, which is a matter for consideration in the short-term. National upscaling of $\mathrm{CMC}$ requires effective change management processes to deliver operative service implementation. In light of the overwhelming evidence of improved holistic outcomes, ${ }^{4,5}$ now is the time for midwives to engage with the new 'The Best Start' ${ }^{1} \mathrm{CMC}$ model of maternity care provision.

\section{References}

1. Scottish Government. The Best Start: a five-year forward plan for maternity and neonatal care in Scotland;2017. Access: www.gov.scot/Resource/0051/00513178.pdf

2. Renfrew MJ., McFadden A, Baston $\mathrm{H}$ et al. Midwifery and quality care: findings from a new evidence-informed framework for maternal and newborn care. The Lancet 2014;9-25.

3. Department of Health (DH). Expert maternity group, changing childbirth document. HMSO, London; 1993.

4. Sandall J., Soltani H., Gates S., Shennan A., Devane D. Midwife-led continuity models versus other models of care for childbearing women. Cochrane Database Syst Rev, 4, CD004667;2016. 
5. Homer C., Leap N., Edwards N., Sandall J. (2017). Midwifery continuity of care in an area of high socio-economic disadvantage in London: a retrospective analysis of Albany Midwifery Practice outcomes using routine data (1997-2009). Midwifery 2017;48,1-10.

6. Dixon L., Guilliland K., Pallant J., Sidebotham M., Fenwick J., McAra-Couper J., Gilkison A. The emotional wellbeing of New Zealand midwives: comparing responses for midwives in caseloading and shift work settings. New Zealand College of Midwives Journal 2017;53,5-14.

7. Menke J, Fenwick J, Gamble J, Brittain H., Creedy DK. Midwives' perceptions of organisational structures and processes influencing their ability to provide caseload care to socially disadvantaged and vulnerable women. Midwifery 2014;30(10),1096-1103.

8. Forster DA, McKay H, Davey MA, Small R, Cullinane F, Newton M, Powell R, McLachlan HL. Women's views and experiences of publicly-funded homebirth programs in Victoria, Australia: A cross-sectional survey. Women \& Birth 2019;32(3),221-230.

9. Hewitt L, Priddis H, Dahlen HG. What attributes do Australian midwifery leaders identify as essential to effectively manage a Midwifery Group Practice? Women \& Birth 2019;32(2),168177.

10. Fernandez Turienzo C, Roe Y, Rayment-Jones H, Kennedy A, Forster D, Homer CSE, McLachlan $\mathrm{H}$, Sandell J. Implementation of midwifery continuity of care models for Indigenous women in Australia: Perspectives and reflections for the United Kingdom. Midwifery 2019;69,110-112.

11. Cummins A, Coddington R, Fox D, Symon A. Exploring the qualities of midwifery-led continuity of care in Australia (MiLCCA) using the quality maternal and newborn care. Midwifery 2019 Doi: 10.1016/j.wombi.2019.03.013

12. Dawson K., McLachlan H., Newton M., Forster D. (2016). Implementing caseload midwifery: exploring the views of maternity managers in Australia: a national cross-sectional survey. Women And Birth: Journal Of The Australian College Of Midwives 2016;29(3),214-222.

13. Sidebotham M., Fenwick J., Rath S., Gamble J. Midwives' perceptions of their role within the context of maternity service reform: an Appreciative Inquiry, Women And Birth: Journal Of The Australian College Of Midwives 2015;28(2),112-120.

14. McCourt C. Organising safe and sustainable care in alongside midwifery units: findings from an organisational ethnographic study. Midwifery 2018;65,26-34.

15. Care Quality Commission (CQC); 2019. Access at: https://www.cqc.org.uk/publications/surveys/surveys

16. McInnes RJ., Hollins Martin CJ., McArthur, J. Midwifery continuity of carer: developing a realist evaluation framework to evaluate the implementation of strategic change in Scotland Midwifery 2018;66,103-110.

(C2019, Elsevier. This manuscript version is made available under the CC-BY-NC-ND 4.0 license http://creativecommons.org/licenses/by-nc-nd/4.0/ 
17. Royal College of Midwives. Why midwives leave: October 2016. Access: https://www.rcm.org.uk/sites/default/files/Why\%20Midwives\%20Leave\%20Revisted\%20\%200ctober\%202016.pdf

18. Friedman HS, Liang M, Banks JL. Measuring the cost-effectiveness of midwife-led versus physician-led intrapartum teams in developing countries Womens Health 2015;11(4),553-564.

19. Hatem M, Sandall J, Devane D, Soltani H, Gates S. Midwife-led versus other models of care for childbearing women. Cochrane Database Syst. Rev. (4), CD004667 (2008).

20. WHO. Midwife-led versus other models of care for childbearing women. 2016 http://apps.who.int/rhl/pregnancy childbirth/antenatal care/general/ cd004667_Wiysongecs_com/en.

21. Pawson R., Tilley N. Realistic Evaluation. London, SAGE; 1997.

22. NHS Scotland. The Warwick-Edinburgh Mental Well-being Scale (WEMWBS); 2006. Available at http://www.healthscotland.scot/tools-and-resources/wemwbs [accessed 26-4-18].

23. Stamm BH. ProQoL:Compassion Satisfaction and Compassion Fatigue, Burnout, Secondary Traumatic Stress; 2009. Available at: http://www.proqol.org [Accessed 26-4-18]

24. Reime B., Klein M., Kelly A., Duxbury N., Saxell L., Liston R et al. Do maternity care provider groups have different attitudes towards birth? BJOG 2004;111(12),1388-1393.

25. Matthews A., Scott PA., Gallagher P. The development and psychometric evaluation of the Perceptions of Empowerment in Midwifery Scale. Midwifery.2009;25(3),327-335.

26. Turnbull D., Reid M., McGinley M., Sheilds NR. Changes in midwives' attitudes to their professional role following the implementation of the midwifery development unit. Midwifery $1995 ; 11(3), 110-9$.

27. Thomas J. Paranjothy S. National Sentinel Caesarean Section Audit Report, Royal College of Obstetricians and Gynaecologists Clinical Effectiveness Support Unit; 2001.

28. Fenwick J., Sidebotham M., Gamble J., Creedy DK. The emotional and professional wellbeing of Australian midwives: a comparison between those providing continuity of midwifery care and those not providing continuity. Women and Birth 2017;31(1),38-43.

29. Banovcinova L., Baskova M. Sources of work-related stress and their effect on burnout in midwifery. Procedia-Social and Behavioral Sciences 2014;132,248-254. 
30. Harris F., Teijlingen E., Hundley V., Farmer J., Bryers H., Caldow J., Ireland J., Kiger A., Tucker J. (2011). The buck stops here: midwives and maternity care in rural Scotland. Midwifery 2011;27(3),301-307.

31. Alexander CR., Bogossian F. Midwives and clinical investigation: a review of the literature. Women and Birth 2018;31(6),442-452.

32. Yilmaz D., Kılıçoğlu G. Resistance to change and ways of reducing resistance in educational organizations. European Journal of Research on Education 2013;1(1),14-21.

33. NHS Service Delivery and Organisation. Managing change in the NHS. NHS R\&D Programme; 2001. https://www.who.int/management/makinginformeddecisions.pdf [accessed 16-4-19]

34. Baker DB., Benjamin Jr., Ludy T. The affirmation of the scientists-practitioner: a look back at boulder. American Psychologist 2000;55(2),241-247.

35. Pinder CC. Work motivation in organizational behavior (2nd ed.), New York, Psychology Press; 2008.

36. Deckers L. Motivation: Biological, psychological and environmental (3rd ed.), ( $\mathrm{p} 2-3$ ). Boston (MA), Pearson; 2010.

37. Mitchell TR., Daniels D. Motivation (Chapter 10)(pp 225-54). In: Borman, D.R., Ilgen, R.J., Klimoski, R.J. (eds.). Handbook of Psychology (Vol 12): Industrial Organizational Psychology, New York, Wiley; 2003.

38. Vinchur AJ., Koppes LL. A historical survey of research and practice in industrial and organizational psychology. In: Zedeck, S. (ed.), APA handbook of industrial and organizational psychology, Washington DC, American Psychological Association; 2010.

39. Griffin MA., Clarke S. Stress and well-being at work. In: Zedeck S. (ed), APA handbook of industrial and organizational psychology. Washington (DC): American Psychological Association; 2010.

40. Spector PE., Fox S. The stressor-emotion model of counterproductive work behavior. In S. Fox and P.E. Spector (eds.). Counterproductive workplace behavior: investigations of actors and targets (pp 151-174), Washington DC: American Psychological Association; 2005.

41. Clarke S. Safety leadership: a meta-analytic review of transformational and transactional leadership styles as antecedents of safety behaviours. Journal of Occupational and Organizational Psychology 2014;86,22-49.

42. Dollard M., Bakker A. Psychosocial safety climate as a precursor to conducive work environments, psychological health problems, and employee engagement. Journal of Occupational and Organizational Psychology 2010;83,579-599.

(C2019, Elsevier. This manuscript version is made available under the CC-BY-NC-ND 4.0 license http://creativecommons.org/licenses/by-nc-nd/4.0/ 
43. Jepsen I., Juul S., Foureur M., Sørensen EE., Nøhr EA. Is caseload midwifery a healthy workform: a survey of burnout among midwives in Denmark. Sexual and Reproductive Healthcare 2017;11(Supplement C),102-106.

44. Newton MS., McLachlan HL., Forster DA., Willis KF. Understanding the 'work' of caseload midwives: a mixed-methods exploration of two caseload midwifery models in Victoria, Australia. Women And Birth: Journal Of The Australian College Of Midwives 2016;29(3),223233.

45. Pallant JF., Dixon L., Sidebotham M., Fenwick J. Further validation of the perceptions of empowerment in midwifery scale. Midwifery 2015;31(10),941-945.

46. Jex SM., Britt TW. Organizational psychology, Hoboken (NJ), Wiley; 2008.

47. Haines VY., Taggar S. (2006). Antecedents of team reward attitude. Group Dynamics: Theory, Research and Practice 2006;10, 194-205.

48. Schultz DP., Sydney E. Psychology and work today: an introduction to industrial and organizational psychology (10th ed.). Upper Saddle River (NJ), Prentice Hall; 2010.

49. Gray J, Taylor J, Newton, M. Embedding continuity of care experiences: an innovation in midwifery education. Midwifery. 2016;33,40-42.

50. Burchell M, Robin, J. The great workplace. New York: The Great Workplace Institute, New York; 2011.

Table 1: Scales embedded in the midwives CMC evaluation tool

\begin{tabular}{|l|l|}
\hline Scales used & Scale description \\
\hline $\begin{array}{l}\text { Continuity of } \\
\text { carer Statements }\end{array}$ & $\begin{array}{l}13 \text { statements about continuity of care models developed from stakeholder } \\
\text { interviews and literature reviews }\end{array}$ \\
\hline
\end{tabular}

(C2019, Elsevier. This manuscript version is made available under the CC-BY-NC-ND 4.0 license http://creativecommons.org/licenses/by-nc-nd/4.0/ 


\begin{tabular}{|c|c|}
\hline $\begin{array}{l}\text { (not previously } \\
\text { tested) } \\
\text { (Survey Q24) }\end{array}$ & $\begin{array}{l}\text { Scoring: each statement is scored from } 1 \text { (strongly disagree) to } 5 \text { (strongly agree). } \\
\text { Negative items are reverse scored. Higher scores are more pro-MLCC. }\end{array}$ \\
\hline $\begin{array}{l}\text { Birth Attitude } \\
\text { Scale (adapted } \\
\text { from Reime et al, } \\
2004 \text { ) } \\
\text { (Survey Q27) }\end{array}$ & $\begin{array}{l}13 \text { items from original } 20 \text { item Birth Attitude Scale - items were removed which did } \\
\text { not fit the role of UK midwives. (Original scale Cronbach's } \alpha: 0.83 \text {, tested with } \\
\text { midwives, family physicians, obstetricians) } \\
\text { Scoring: each statement is scored from } 1 \text { (strongly disagree) to } 5 \text { (strongly agree). } \\
\text { Negative items are reverse scored. Higher scores are more pro-normal birth }\end{array}$ \\
\hline $\begin{array}{l}\text { Attitude to } \\
\text { professional role } \\
\text { scale (Turnbull et } \\
\text { al., 1995) } \\
\text { (Survey Q28) }\end{array}$ & $\begin{array}{l}20 \text { item scale (tested with midwives) with } 4 \text { subscales: } \\
\text { - Professional satisfaction ( } 6 \text { items), e.g., I am in a rut } \\
\text { - Professional support ( } 5 \text { items), e.g., I get professional support from my } \\
\text { colleagues } \\
\text { - Client interaction (4 items), e.g., my current role allows me to plan care with } \\
\text { women } \\
\text { - Professional development (5 items), e.g., I have enough professional } \\
\text { independence } \\
\text { Scoring: each statement is scored from }-2 \text { (strongly disagree) to }+2 \text { (strongly } \\
\text { agree). Negative items are reverse scored. Max score }=40, \text { min }=-40 \text {. Higher } \\
\text { scores are more positive: }\end{array}$ \\
\hline $\begin{array}{l}\text { Professional Role } \\
\text { statements (RCM, } \\
2015) \\
\text { (Survey Q29) }\end{array}$ & $\begin{array}{l}7 \text { professional role statements, with } 2 \text { sub scales: } \\
\text { - Working as a midwife ( } 3 \text { items), e.g., I am proud to work as a midwife } \\
\text { - Working for the organisation ( } 4 \text { items), e.g., I would recommend my } \\
\text { organisation as a great place to work } \\
\text { Scoring: each statement is scored from } 1 \text { (strongly disagree) to } 5 \text { (strongly agree). } \\
\text { Negative items are reverse scored. Higher scores are more positive. }\end{array}$ \\
\hline $\begin{array}{l}\text { Perceptions of } \\
\text { Empowerment } \\
\text { Scale (Matthews } \\
\text { et al, 2009, } \\
\text { Pallant et al., } \\
\text { 2015) } \\
\text { (Survey Q30) }\end{array}$ & $\begin{array}{l}\text { 19 item scale with } 4 \text { subscales: } \\
\text { - Autonomy/empowerment (4 items): e.g., I am an advocate for birthing women } \\
\text { - Manager support (5 items): e.g., I am valued by my manager } \\
\text { - Professional recognition (5 items): e.g., I am recognised as a professional by } \\
\text { the medical staff } \\
\text { - Skills and resources ( } 5 \text { items): e.g., I have adequate resources for birthing } \\
\text { women in my care. } \\
\text { Scoring: each statement is scored from } 1 \text { (strongly disagree) to } 5 \text { (strongly agree). } \\
\text { Negative items are reverse scored. Higher scores are more positive. }\end{array}$ \\
\hline $\begin{array}{l}\text { Professional } \\
\text { Quality of Life } \\
\text { (ProQol ) scale, } \\
\text { Stamm et al., } \\
2009 \\
\text { (Survey Q31) }\end{array}$ & $\begin{array}{l}\text { 30 statements with } 3 \text { subscales: } \\
\text { - Compassion Satisfaction (10 items): e.g., I believe I can make a difference } \\
\text { through my work (high scores are more positive) } \\
\text { - Burnout ( } 10 \text { items): e.g., I am happy (low scores are more positive) } \\
\text { - Secondary Traumatic Stress (10 items), e.g., I jump or am startled by } \\
\text { unexpected sounds (low scores are more positive) } \\
\text { Scoring each statement is scored from } 1 \text { (never) to } 5 \text { (very often). Positive items } \\
\text { on the burnout scale are reverse scored. Score ranges from } \leq 22 \text { (low score); 23- } \\
41 \text { average score } \& \geq 42 \text { high score. }\end{array}$ \\
\hline $\begin{array}{l}\text { Warwick } \\
\text { Edinburgh Mental } \\
\text { Wellbeing Short } \\
\text { (WEMWBS) } \\
\text { Scale } \\
\text { (Survey Q36) }\end{array}$ & $\begin{array}{l}\text { Seven questions scored from } 1 \text { (none of the time) to } 5 \text { (all of the time). Maximum } \\
\text { score is } 35 \text { and is most positive score. Scores need to be converted to compare } \\
\text { with } 14 \text { item scale. }\end{array}$ \\
\hline
\end{tabular}

\section{Table 2: Comparison of background variables between hospital and community midwifery staff groups and results of inferential statistical testing}




\begin{tabular}{|c|c|c|c|c|c|}
\hline \multicolumn{2}{|l|}{ Variable } & \multicolumn{2}{|l|}{ Setting } & \multicolumn{2}{|l|}{ Analysis } \\
\hline Age & $\begin{array}{l}\text { Hospital A } \\
\text { (n) }\end{array}$ & $\begin{array}{l}\text { Hospital B } \\
\text { (n) }\end{array}$ & $\begin{array}{l}\text { Community } \\
\text { (n) }\end{array}$ & $\begin{array}{l}\text { Test } \\
\text { statistic }\end{array}$ & $p$ \\
\hline$<30$ & 19 & 3 & 10 & $\chi^{2}(\mathrm{df}=6)=24.70$ & $<0.001$ \\
\hline $31-40$ & 30 & 5 & 8 & & \\
\hline $41-50$ & 28 & 6 & 26 & & \\
\hline$>50$ & 17 & 9 & 40 & & \\
\hline \multicolumn{6}{|c|}{ Years qualified } \\
\hline$<5$ & 33 & 4 & 22 & $\chi^{2}(\mathrm{df}=6)=32.00$ & $<0.001$ \\
\hline$>5-10$ & 31 & 3 & 10 & & \\
\hline$>10-20$ & 56 & 15 & 27 & & \\
\hline$>20$ & 30 & 12 & 60 & & \\
\hline \multicolumn{6}{|c|}{ Years working in Health Board } \\
\hline$<5$ & 50 & 7 & 24 & $\chi^{2}(\mathrm{df}=6)=28.59$ & $<0.001$ \\
\hline$>5-10$ & 17 & 1 & 14 & & \\
\hline$>10-20$ & 57 & 18 & 30 & & \\
\hline$>20$ & 27 & 8 & 51 & & \\
\hline \multicolumn{6}{|c|}{ Live in Health Board } \\
\hline No & 30 & 10 & 12 & $\chi^{2}(\mathrm{df}=2)=9.69$ & 0.008 \\
\hline Yes & 118 & 21 & 105 & & \\
\hline \multicolumn{6}{|c|}{ Education } \\
\hline College & 14 & 8 & 19 & $\chi^{2}(\mathrm{df}=4)=5.71$ & 0.222 \\
\hline Degree & 68 & 14 & 52 & & \\
\hline Postgrad & late 11 & 1 & 10 & & \\
\hline \multicolumn{6}{|c|}{ Work status } \\
\hline Part-time & 77 & 24 & 54 & $\chi^{2}(\mathrm{df}=2)=6.24$ & 0.044 \\
\hline Full-time & 75 & 11 & 67 & & \\
\hline \multicolumn{6}{|c|}{ Work shifts } \\
\hline No & 22 & 7 & 114 & $\chi^{2}(\mathrm{df}=2)=183.32$ & $<0.001$ \\
\hline Yes & 130 & 28 & 7 & & \\
\hline \multicolumn{6}{|c|}{ Work overtime } \\
\hline No & 75 & 19 & 45 & $\chi^{2}(\mathrm{df}=2)=5.36$ & $<0.069$ \\
\hline Yes & 76 & 15 & 74 & & \\
\hline \multicolumn{6}{|l|}{ On call } \\
\hline No & 151 & 34 & 5 & $\chi^{2}(\mathrm{df}=2)=279.40$ & $<0.001$ \\
\hline Yes & 1 & 1 & 116 & & \\
\hline
\end{tabular}


Table 3: Comparison of self-report measures as a function of hospital or community-based setting. Standard deviations are in parentheses, $\mathrm{ES}=$ effect size

\begin{tabular}{|c|c|c|c|c|c|c|c|}
\hline Scale & Hospital A & Hospital B & Community & $F(d f)$ & $p$ & ES & $N(A, B$, Comm. $)$ \\
\hline$\underline{W E M W B S}$ & $26.22(5.98)$ & $26.40(7.33)$ & $25.93(5.59)$ & $0.08(2,203)$ & 0.93 & $<0.001$ & $97 / 23 / 86$ \\
\hline \multicolumn{8}{|l|}{ ProQOL (Compassion) } \\
\hline Second. Trau. Str & $19.78(5.91)$ & $22.52(7.88)$ & $20.18(4.90)$ & $2.11(2,204)$ & 0.12 & 0.02 & \multirow[t]{3}{*}{$97 / 23 / 87$} \\
\hline Satisfaction & $39.39(5.65)$ & $39.22(4.97)$ & $40.21(5.33)$ & $0.62(2,204)$ & 0.54 & 0.006 & \\
\hline Burnout & $23.37(5.75)$ & $24.22(5.45)$ & $22.41(5.30)$ & $1.25(2,204)$ & 0.29 & 0.01 & \\
\hline \multicolumn{2}{|c|}{ Birth Attitude Scale 42.70 (5.05) } & $43.79(4.67)$ & $45.62(4.21)$ & $9.69(2,223)$ & $<0.001$ & 0.08 & $111 / 24 / 91$ \\
\hline \multicolumn{8}{|c|}{ Professional role: } \\
\hline Midwifery & $11.81(2.20)$ & $11.00(2.87)$ & $11.64(2.07)$ & $1.27(2,213)$ & 0.28 & 0.01 & \multirow[t]{3}{*}{$103 / 24 / 89$} \\
\hline Organisation & $14.52(3.31)$ & $14.08(3.97)$ & $14.34(3.20)$ & $0.20(2,213)$ & 0.82 & 0.001 & \\
\hline Total & $26.33(5.25)$ & $25.08(6.44)$ & $25.98(4.98)$ & $0.56(2,213)$ & 0.58 & 0.005 & \\
\hline \multicolumn{8}{|l|}{ PES-M: } \\
\hline$\overline{\text { Skills/resources }}$ & $4.05(0.51)$ & $3.98(0.55)$ & $4.04(0.43)$ & $0.20(2,208)$ & 0.82 & 0.002 & \multirow[t]{4}{*}{$99 / 24 / 88$} \\
\hline Professional recog. & $3.99(0.60)$ & $3.78(0.62)$ & $3.93(0.53)$ & $1.42(2,208)$ & 0.25 & 0.013 & \\
\hline Manager support & $3.11(0.98)$ & $3.83(0.69)$ & $3.86(0.80)$ & $19.07(2,208)$ & $<0.001$ & 0.16 & \\
\hline Autonomy/empow. & v.3.84 (0.57) & $3.80(0.59)$ & $4.15(0.47)$ & $9.25(2,208)$ & $<0.001$ & 0.08 & \\
\hline \multicolumn{8}{|c|}{ Continuity of Carer Scale: } \\
\hline Attitudes/beliefs & $5.74(2.21)$ & $6.48(2.62)$ & $6.53(2.44)$ & $3.31(2,238)$ & 0.04 & 0.03 & \multirow{4}{*}{$117 / 25 / 99$} \\
\hline Logistics/practical & 13.00 & $14.84(4.75)$ & $16.39(3.53)$ & $21.12(2,238)$ & $<0.001$ & 0.15 & \\
\hline Outcomes & $9.92(3.48)$ & $12.04(3.58)$ & $9.98(3.73)$ & $3.80(2,238)$ & 0.02 & 0.04 & \\
\hline Total & $28.66(8.03)$ & $33.36(9.84)$ & $32.90(8.31)$ & $8.16(2,238)$ & $<0.001$ & 0.06 & \\
\hline$\underline{R C O G 1}$ & $4.36(0.78)$ & $4.32(0.63)$ & $4.43(0.77)$ & $0.28(2,227)$ & 0.76 & 0.002 & $111 / 25 / 94$ \\
\hline$\overline{\underline{R C O G 2}}$ & $2.45(1.06)$ & $2.60(1.22)$ & $2.52(0.92)$ & $0.27(2,227)$ & 0.77 & 0.002 & $111 / 25 / 94$ \\
\hline
\end{tabular}

Note: To control for type 1. error $p$ criteria for statistical significance set at a more conservative 0.01

Second. Trau. Str $=$ Secondary Traumatic Stress 
Table 4: Comparison of Attitude to Professional Role (APRS) scale total and sub-scale scores as a function of hospital or community-based setting. Standard deviations are in parentheses, $\mathrm{CI}=$ confidence interval, $\mathrm{ES}=\mathrm{effect}$ size

\begin{tabular}{|c|c|c|c|c|c|c|c|}
\hline Scale & Hospital A & Hospital B & Community & $F(\mathbf{d f})$ & $p$ & ES & $\mathrm{N}(\mathrm{A}, \mathrm{B}, \mathrm{Comm})$. \\
\hline Satisfaction & $5.34(4.23)$ & $5.00(4.06)$ & $6.48(3.53)$ & $2.53(2,213)$ & 0.08 & 0.02 & $103 / 24 / 89$ \\
\hline Support & $1.38(3.34)$ & $0.00(3.58)$ & $2.30(2.93)$ & $5.38(2,213)$ & 0.005 & 0.05 & \\
\hline Interaction & $2.27(2.83)$ & $1.29(2.56)$ & $3.29(2.36)$ & $6.94(2,213)$ & 0.001 & 0.06 & \\
\hline Development & $2.33(3.34)$ & $2.54(3.74)$ & $4.17(2.82)$ & $8.40(2,213)$ & $<0.001$ & 0.07 & \\
\hline Total score & $11.32(11.63)$ & 8.33 (11.89) & $16.25(9.24)$ & $7.14(2,213)$ & 0.001 & 0.06 & \\
\hline
\end{tabular}

Note: To control for type 1. error $p$ criteria for statistical significance set at a more conservative 0.01 . 
Table 5: Comparison between hospital and community midwifery staff groups as a function of categorical stratification of key measures

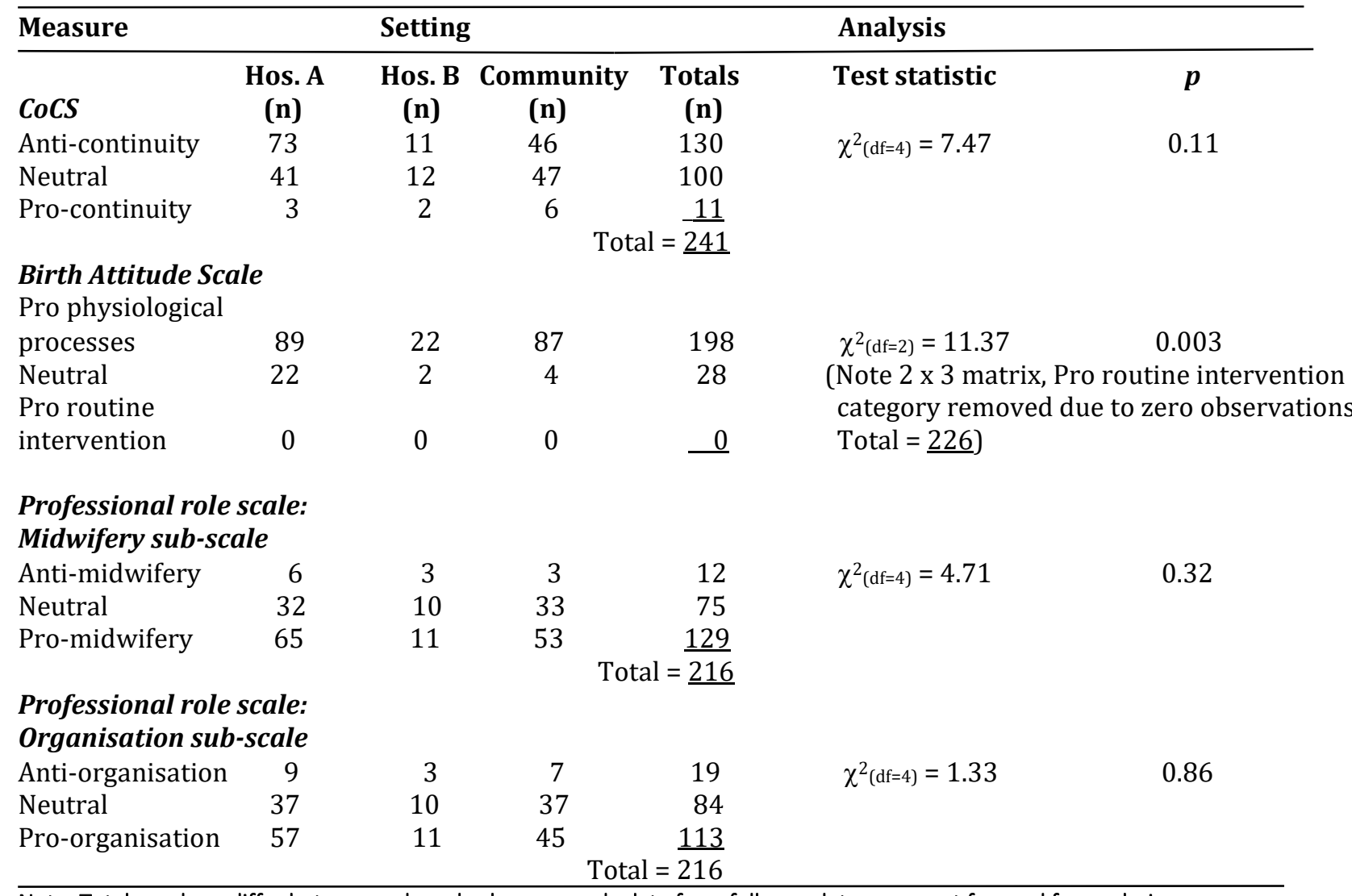

Note: Total numbers differ between sub-scales because only data from full completers was put forward for analysis 
Table 6: Comparison between hospital and community midwifery staff groups as a function of experience of/exposure to a Continuity Midwifery Care (CMC) model and work model preference

\begin{tabular}{|c|c|c|c|c|c|c|}
\hline \multirow[t]{2}{*}{ Question } & \multirow[b]{2}{*}{$\begin{array}{l}\text { Hos. A } \\
\text { (n) }\end{array}$} & \multicolumn{2}{|c|}{ Setting } & \multicolumn{3}{|c|}{ Analysis } \\
\hline & & $\begin{array}{l}\text { Hos. B } \\
\text { (n) }\end{array}$ & $\begin{array}{l}\text { Community } \\
\text { (n) }\end{array}$ & $\begin{array}{l}\text { Totals } \\
\text { (n) }\end{array}$ & Test statistic & $p$ \\
\hline \multicolumn{7}{|c|}{ Antenatal continuity } \\
\hline No & 81 & 15 & 25 & 121 & \multirow[t]{2}{*}{$\chi^{2}(\mathrm{df}=2)=41.20$} & \multirow[t]{2}{*}{$<0.001$} \\
\hline Yes & 35 & 10 & 71 & 116 & & \\
\hline \multicolumn{7}{|c|}{ Antenatal and postnatal continuity } \\
\hline No & 46 & 13 & 7 & 66 & \multirow{2}{*}{$\chi^{2}(\mathrm{df}=2)=35.50$} & \multirow[t]{2}{*}{$<0.001$} \\
\hline Yes & 70 & 12 & 89 & 171 & & \\
\hline \multicolumn{7}{|c|}{ Team Midwifery care } \\
\hline No & 83 & 16 & 61 & 160 & \multirow[t]{2}{*}{$\chi^{2}(\mathrm{df}=2)=1.69$} & \multirow[t]{2}{*}{0.43} \\
\hline Yes & 33 & 9 & 35 & 77 & & \\
\hline \multicolumn{7}{|c|}{ Midwifery group practice caseload care } \\
\hline No & 107 & 21 & 74 & 202 & \multirow[t]{2}{*}{$\chi^{2}(\mathrm{df}=2)=9.62$} & \multirow[t]{2}{*}{0.008} \\
\hline Yes & 9 & 4 & 22 & 35 & & \\
\hline \multicolumn{7}{|c|}{ One-to-one caseload care } \\
\hline No & 109 & 25 & 88 & 222 & \multirow[t]{2}{*}{$\chi^{2}(\mathrm{df}=2)=2.36$} & \multirow[t]{2}{*}{0.31} \\
\hline Yes & 7 & 0 & 8 & 15 & & \\
\hline \multicolumn{7}{|l|}{ Preference } \\
\hline Antenat. Cont. & 25 & 3 & 17 & 45 & \multirow[t]{6}{*}{$\chi^{2}(\mathrm{df}=2)=39.56$} & \multirow[t]{6}{*}{$<0.001$} \\
\hline Postnat. Cont. & t. 27 & 7 & 50 & 84 & & \\
\hline Team Midwif. & 19 & 9 & 13 & 41 & & \\
\hline MGP & 10 & 4 & 9 & 23 & & \\
\hline 1 to 1 Caseloa & ad 2 & 0 & 2 & 4 & & \\
\hline Other & 33 & 2 & 5 & 40 & & \\
\hline
\end{tabular}

